Research Article

\title{
Modern Contraceptive Use and Influencing Factors in Amhara Regional State: Further Analysis of Ethiopian Demographic Health Survey Data 2016
}

\author{
Melash Belachew Asresie ${ }^{(D},{ }^{1}$ Gedefaw Abeje Fekadu ${ }^{10},{ }^{1}$ Gizachew Work Dagnew (iD, 1 \\ and Yared Mulu Gelaw² \\ ${ }^{1}$ Department of Reproductive Health and Population Studies, School of Public Health, College of Medicine and Health Science, \\ Bahir Dar University, Bahir Dar, Ethiopia \\ ${ }^{2}$ Department of Health Service Management and Health Informatics, School of Public Health, \\ College of Medicine and Health Science, Bahir Dar University, Bahir Dar, Ethiopia
}

Correspondence should be addressed to Melash Belachew Asresie; kalleab1@gmail.com

Received 8 February 2020; Revised 11 April 2020; Accepted 15 June 2020; Published 23 July 2020

Academic Editor: Jagdish Khubchandani

Copyright (c) 2020 Melash Belachew Asresie et al. This is an open access article distributed under the Creative Commons Attribution License, which permits unrestricted use, distribution, and reproduction in any medium, provided the original work is properly cited.

\begin{abstract}
Background. Ethiopia is one of the Sub-Saharan African countries with a high unmet need for contraceptives. Contraception is a good indicator of the extent to which couples have access to reproductive health services. A study on contraceptives can provide overall direction by helping to identify the obstacles in society and weaknesses in services that need to be overcome. However, little is known in Amhara region context. Therefore, this analysis was aimed to assess modern contraceptive use and influencing factors in the Amhara regional state of Ethiopia. Methods. We used secondary data analysis of the regional representative sample of women aged 15-49 years from the 2016 Ethiopian Demography and Health Survey (EDHS). A total of 2207 married reproductiveage women (15-49 years) selected using a two-stage stratified cluster sampling technique were included in this analysis. Both descriptive and logistic regression analyses were performed using STATA V.14. A 95\% confidence interval was used to declare statistical significance. Results. Modern contraceptive use among married reproductive-age women was 51.3\% (95\% CI: 47.0-55.6). Being from households with rich wealth index ( $\mathrm{AOR}=1.6 ; 95 \% \mathrm{CI}$ : 1.1-2.5), a secondary or higher level of education $(\mathrm{AOR}=3.0$; 95\% CI: 1.4-6.2), and desire to space (AOR = 2.6; 95\% CI: 1.9-3.7) or want no more child (AOR = 2.4; 95\% CI: 1.6-3.5) were found positively associated with modern contraceptive use. On the other hand, modern contraceptive use was negatively associated with women aged $35-49$ years $(\mathrm{AOR}=0.7 ; 95 \% \mathrm{CI}$ : 0.5-0.9). Conclusion. Modern contraceptive use was relatively high in the Amhara region. The odds of modern contraceptive use were higher among women with secondary or more educational levels. Women from households with rich wealth index and those who want to delay or avoid pregnancy had also more odds of using modern contraceptives. Therefore, strengthening women's and community education could improve modern contraceptive use. Moreover, more emphasis should be given for income generation activities.
\end{abstract}

\section{Background}

Family planning (FP), defined as the ability of individuals and couples to have the number of children when they want, is a proven strategy to reduce maternal and child morbidity and mortality $[1,2]$. Recent studies identified that contraceptive use can reduce almost 230 million births every year $[3,4]$. Another study showed that contraceptive use alone can reduce maternal mortality by $44 \%$ [5]. Despite these benefits, modern contraceptive (MC) use among married or in-union reproductive-age women remains low. According to the 2017 Global Report, MC use among these women was $58 \%$ globally and $32 \%$ in Africa [6]. In developing countries, about 214 million married or in-union reproductive-age women had an unmet need for MC in 2018 [7]. If the world fails to supply this demand, women pay the price of 
unintended pregnancy and abortions, which can sometimes be unsafe. In 2015, almost half (44\%) of global pregnancies were unintended and two-fifth of these pregnancies ended with abortion $[8,9]$.

Modern FP service was introduced to Ethiopia by the Family Guidance Association of Ethiopia in 1966. The FP service at this time was mainly awareness creation due to social and political constraints. In 1993, the country adopted the population policy, and in 1996, the minister of health released FP guidelines to guide stakeholders on family planning service provision [10]. In 2003, Ethiopia launched the health extension program. FP service is one of the 16 packages in this program [11]. Using this and other programs, the health sector transformation plan planned to increase the contraceptive prevalence rate (CPR) to $55 \%$ and reduce the unmet need to $10 \%$ by the end of 2020 at national and regional levels [12]. Regardless of these efforts, $\mathrm{MC}$ use is low and unmet need is high in Ethiopia. According to the 2019 Ethiopia Mini Demographic and Health Survey (EDHS) report, only $41 \%$ of married reproductive-age women were using MC [13]. Surveys in Ethiopia showed MC use varied by regions $[14,15]$.

Unintended pregnancy is a public health problem in Amhara regional state [16-19]. Almost one in four married women who want to delay or avoid pregnancy in the Amhara region was not using MC, and each woman experienced at least one unplanned birth [15]. Some studies in the Amhara region showed that contraceptive use is public health problem [20,21], but studies about factors affecting $\mathrm{MC}$ use among married or in-union women are limited. The objective of this study, therefore, was to assess modern contraceptive use and its associated factors among married nonpregnant reproductive-age women in the Amhara region.

\section{Methods}

2.1. Data Source. We used secondary community-based cross-sectional regional representative 2016 EDHS data collected through a two-stage stratified cluster sampling technique from January 18, 2016, to June 27, 2016. The survey was implemented by the Central Statistical Agency (CSA) at the request of the Federal Minister of Health (FMOH) [15].

Initially, each region in the EDHS was stratified into urban and rural areas yielding 21 sampling strata. After strata, there were 84,915 enumeration areas. From these, a total of 645 enumeration areas (202 in urban areas and 443 in rural areas) were independently selected proportionally based on the 2007 Ethiopia Population and Housing Census [15]. The survey covered 17,067 households, yielding response rate $98 \%$, and 15,863 women, yielding response rate $95 \%$. All women aged 15 to 49 years who were either permanent residents of the selected households or visitors who stayed in the selected household the night before the survey were eligible for the study. Of these 15,683 women, 3714 were from Amhara regional state, contributes $22 \%$ of national women. The analysis was restricted to married or inunion women (2414) [15]. Women who were pregnant or amenohearric at the time of the survey (207) also were excluded. Finally, 2207 nonpregnant married or in-union reproductive-age women were included in the final model (Figure 1).

\subsection{Study Variables}

2.2.1. Outcome Variables. The outcome variable for this analysis was modern contraceptive use, which has two categories (yes or no). The 2016 EDHS questionnaire asked all reproductive-age women involved in the survey whether they were using contraceptives including the type of contraceptive. A woman was considered "using modern contraceptives" if she reported that she was using sterilization (tuba ligation or vasectomy), intrauterine device (IUD), injectable, oral contraceptive (pills), or condom at the time of the survey.

2.2.2. Independent Variables. Demographic and socioeconomic variables are included in the analysis as predictor variables. Demographic variables included were as follows: age of women (15-34 or 35-49), family size $(\leq 4,5-8$,or $\geq 9)$, age at first marriage $(15-18,19-24$, or $\geq 25)$, number of living children (0.1-2, 3-4, or $\geq 5)$, number of children ever birth $(0,1-2,3-4$, or $\geq 5)$, ideal number of children $(\leq 3$ or $>3)$, future fertility preference (want more soon (within two years), want later (two years later), want time not decided, undecided, or want no more), knowledge on modern contraceptive (yes or no), and women's religion (orthodox, Muslim) are included. Socioeconomic variables included were as follows: residence (urban or rural), women's and partners' educational status (no, primary, secondary, or above), women's and partners' occupation (not working or working), wealth index (poor, middle, or rich), exposure to FP messages on mass media (yes or no), and visits by health workers and health facility visit (yes or no). The exposure to FP messages on mass media was constructed from other data (if women heard or saw family planning messages from radio, television, magazine, or phone message). The poor wealth index category was created by merging poorer and poorest, and the variable rich was constructed by merging richer and richest.

2.3. Statistical Analysis. Weighted data were analyzed with a complex survey sampling analysis technique using STATA software version 14.1. Frequency distribution and descriptive statistics (mean \pm standard deviation (SD)) were used to describe the characteristics of the study participants. Chisquare analysis was also used to describe the relationship of independent variables and dependent variables. Bivariable and multivariable logistic regression analyses were done to identify factors associated with modern contraceptive use. Variables are significant with $95 \%$, and $p$ value $<=0.05$ in the multivariable analysis was used to declare association. Multicollinearity with variance inflation factor was less than ten was checked before multivariable logistic regression 


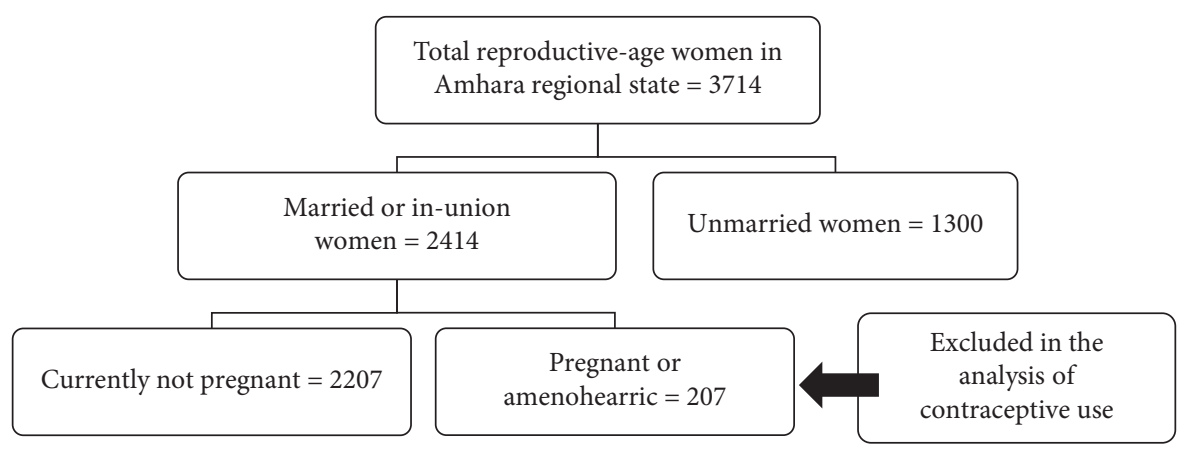

FIGURE 1: Schematic presentation to select women included in the analysis in Amhara region, Ethiopia 2016 EDHS.

analysis was done. The goodness of fit of the final model was tested by Hosmer-Lemeshow ( $p$ value $>0.05$ ).

\section{Result}

3.1. Sociodemographic and Other Characteristics of Women. A total of 2207 reproductive-age married women were included in the analysis. The mean age of women was 32.0 years ( $S D \pm 0.3$ years). About three-fifth $(61.0 \%)$ of women were aged 15-34 years. About $15.8 \%$ of women were Muslim, with the rest orthodox (84.2\%). The majority of women $(84.2 \%)$ were rural residents. The majority of women $(81.6 \%)$ were married or in-union before their $19^{\text {th }}$ birthday. About two-thirds $(69.1 \%)$ of women were not educated. Almost half (52.2\%) of women reported that they visited a health facility, and only $31.6 \%$ of women were visited by health workers at home 12 months before the survey. Almost one-fourth $(24.0 \%)$ of women reported that they heard or saw family planning messages through radio, television, magazine, or phone message.

About $89.4 \%$ of women were having at least one living child, of which about $28.6 \%$ had five or above living children. The mean number of living children was 3.3 children per woman (SD + 0.1children). Thirty-seven percent of women reported that they want no more children and $19.1 \%$ want within two years (Table 1).

3.2. Contraceptive Use. Of all married reproductive-age women, half of them $(51.3 \%)$ were using modern contraceptives and $0.5 \%$ were using traditional methods. Of modern contraceptive users, the majority of them $(62.4 \%)$ were using injectable followed by implant/Norplant $(25.8 \%)$. About two-thirds (67.5\%) of women wanted to use contraceptives to limit or spacing their birth (Table 2).

\subsubsection{Modern Contraceptive Use by Women's Characteristics.} Modern contraceptive use varied by women's age. The level of modern contraceptive use among women aged 15-34 years was $57.4 \%$ higher compared to women aged $35-49$ years $(p<0.001)$. Modern contraceptive use also varied by women's educational status. About $76.1 \%$ of women with secondary or above educational level were using modern contraceptives higher compared to women with no education $(45.9 \%)(p<0.001)$. About two-thirds $(65.7 \%)$ of women whose husband with secondary or above educational level used modern contraceptives higher compared to women whose husband with no education (46.6\%) $(p=0.003)$. Modern contraceptive use decreased as the number of living children increases. About $60.8 \%$ of women who had no living children used modern contraceptives compared to $36.6 \%$ of women who had five or more living children $(p<0.001)$. About $57.4 \%$ of women who received family planning messages used modern contraceptives compared to women not received messages $(49.4 \%)$ ( $p=0.040$ ). About $56.0 \%$ of women who visited by health workers used modern contraceptives compared to $46.0 \%$ among women not visited by health workers $(p=0.040)$. There was no statistically significant difference in contraceptive use among married reproductive-age women by religion, occupation, residence, age at first marriage, visit a health facility, and partner occupation (Table 3).

3.2.2. Reason for Not Using Contraceptives. The most common reasons for nonuse of contraceptives among married reproductive-age women were thinking that contraceptives are fatalistic $(17.6 \%)$, menses not returned $(15.2 \%)$, on breastfeeding $(9.1 \%)$, infrequent sex or have no sex $(5.9 \%)$, and fear of side effect $(3.0 \%)$.

3.2.3. Factors Associated with Modern Contraceptive Use. On the bivariable analysis, age, age at first marriage, family size, exposure to FP message, educational status, wealth index, the ideal number of children, future fertility preference, visited by health workers, and residence were significantly associated with modern contraceptive use among married or in-union reproductive-age women. On multivariable analysis, age, future fertility preference, educational status, and wealth index were significantly associated. The odds of modern contraceptive use among women aged 35-49 years were 30\% less compared to women aged 15-34 years $(\mathrm{AOR}=0.7 ; 95 \% \mathrm{CI}: 0.5-0.9)$. Women with a secondary or higher level of education had 3 times $(\mathrm{AOR}=3.0$; 95\% CI: 1.4-6.2) higher odds of modern contraceptive use compared to women with no education. The odds of modern contraceptive use among women who belonged to the rich wealth index were 3 times higher compared to women who were in the poor wealth index category $(\mathrm{AOR}=3.0 ; 95 \% \mathrm{CI}$ : 1.4-6.2) (Table 4). 
TABLE 1: Sociodemographic and other characteristics of married reproductive-age women in the Amhara region, EDHS 2016.

\begin{tabular}{|c|c|}
\hline Variables & Weighted frequency (\%) \\
\hline $\begin{array}{l}\text { Educational status } \\
\text { No education } \\
\text { Primary } \\
\text { Secondary+ } \\
\end{array}$ & $\begin{array}{l}1.526(69.1) \\
452(20.5) \\
229(10.4) \\
\end{array}$ \\
\hline $\begin{array}{l}\text { Occupational status } \\
\text { Not working } \\
\text { Working } \\
\end{array}$ & $\begin{array}{c}863(39.1) \\
1.344(60.9) \\
\end{array}$ \\
\hline $\begin{array}{l}\text { Wealth index } \\
\text { Poor } \\
\text { Middle } \\
\text { Rich }\end{array}$ & $\begin{array}{l}780(35.3) \\
530(24.0) \\
897(40.7) \\
\end{array}$ \\
\hline $\begin{array}{l}\text { Family size } \\
\quad \leq 4 \\
5-8 \\
\geq 9 \\
\end{array}$ & $\begin{array}{c}901(40.8) \\
1.198(54.3) \\
108(4.9) \\
\end{array}$ \\
\hline $\begin{array}{l}\text { Age at first marriage } \\
\leq 18 \\
19-24 \\
\geq 25 \\
\end{array}$ & $\begin{array}{c}1.801(81.6) \\
335(15.2) \\
71(3.2) \\
\end{array}$ \\
\hline $\begin{array}{l}\text { Partner education } \\
\text { No education } \\
\text { Primary } \\
\text { Secondary+ } \\
\text { Do not know }\end{array}$ & $\begin{array}{c}1.389(62.9) \\
508(23.0) \\
276(12.5) \\
34(1.6)\end{array}$ \\
\hline $\begin{array}{l}\text { Partner occupation } \\
\text { Have no work } \\
\text { Have work } \\
\text { Do not know } \\
\end{array}$ & $\begin{array}{c}42(1.9) \\
2.157(97.8) \\
8(0.3) \\
\end{array}$ \\
\hline $\begin{array}{l}\text { Future fertility preference } \\
\text { Want more soon } \\
\text { Want later } \\
\text { Want but time not decided } \\
\text { Undecided } \\
\text { Want no } \\
\text { Declared infecund }\end{array}$ & $\begin{array}{c}422(19.1) \\
742(33.6) \\
62(2.8) \\
116(5.3) \\
816(37.0) \\
49(2.2)\end{array}$ \\
\hline $\begin{array}{l}\text { Number of children ever born } \\
0 \\
1-2 \\
3-4 \\
\geq 5\end{array}$ & $\begin{array}{l}229(10.4) \\
630(28.5) \\
567(25.7) \\
781(35.4)\end{array}$ \\
\hline Number of living children & $\begin{array}{l}233(10.6) \\
712(32.2) \\
631(28.6) \\
631(28.6)\end{array}$ \\
\hline Ideal number of children & $\begin{array}{c}415(18.8) \\
1.477(66.9) \\
315(14.3)\end{array}$ \\
\hline
\end{tabular}

\section{Discussion}

4According to this analysis, $51.3 \%$ (95\% CI: 47.0-55.6) of married or in-union reproductive-age women in Amhara regional were used modern contraceptives. Of which, $63.3 \%$ were for spacing and $36.7 \%$ for limiting. The majority of them (62.4\%) were used injectable followed by implant/ Norplant (25.8\%).
TABle 2: Contraceptive use among married reproductive-age women in the Amhara region, EDHS 2016.

\begin{tabular}{lc}
\hline Variables & Frequency (\%) \\
\hline Contraceptive demand & \\
Demand for spacing & $880(39.9)$ \\
Demand for limiting & $610(27.6)$ \\
\hline Using contraceptives & \\
Using for spicing & $721(32.7)$ \\
Using for limiting & $421(19.1)$ \\
\hline Current use by method & \\
No & $1,065(48.3)$ \\
Traditional & $10(0.5)$ \\
Modern & $1.32(51.3)$ \\
\hline Type of modern method used $(n=1132)$ & \\
Pill & $49(4.3)$ \\
IUD & $72(6.4)$ \\
Injectable & $706(62.4)$ \\
Condom & $0(0.0)$ \\
Sterilization & $13(1.1)$ \\
Implant & $292(25.8)$ \\
\hline
\end{tabular}

TABLE 3: Modern contraceptive use by sociodemographic characteristics of married reproductive-age women in the Amhara region, EDHS 2016.

\begin{tabular}{|c|c|c|}
\hline Variables & MC use, $n(\%)$ & $p$ value \\
\hline $\begin{array}{l}\text { Residence } \\
\text { Urban } \\
\text { Rural } \\
\end{array}$ & $\begin{array}{l}214(61.5) \\
918(49.4)\end{array}$ & 0.064 \\
\hline $\begin{array}{l}\text { Educational status } \\
\text { No education } \\
\text { Primary } \\
\text { Secondary+ } \\
\end{array}$ & $\begin{array}{l}701(45.9) \\
257(56.9) \\
174(76.1) \\
\end{array}$ & $<0.001$ \\
\hline $\begin{array}{l}\text { Religion } \\
\text { Orthodox } \\
\text { Muslim } \\
\end{array}$ & $\begin{array}{l}941(50.6) \\
191(54.9) \\
\end{array}$ & 0.403 \\
\hline $\begin{array}{l}\text { Occupational status } \\
\text { Not working } \\
\text { Working } \\
\end{array}$ & $\begin{aligned} & 0 . 540 \\
& 431(50.0) \\
& 701(52.2) \\
&\end{aligned}$ & \\
\hline $\begin{array}{l}\text { Wealth index } \\
\text { Poor } \\
\text { Middle } \\
\text { Rich } \\
\end{array}$ & $\begin{array}{l}339(43.4) \\
290(54.7) \\
504(56.2)\end{array}$ & 0.022 \\
\hline $\begin{array}{l}\text { Family size } \\
\quad \leq 4 \\
5-8 \\
\geq 9 \\
\end{array}$ & $\begin{array}{c}501(55.6) \\
591(49.4) \\
40(37.1) \\
\end{array}$ & 0.026 \\
\hline $\begin{array}{l}\text { Age at first marriage } \\
\leq 18 \\
19-24 \\
\geq 25 \\
\end{array}$ & $\begin{array}{c}898(49.9) \\
194(57.8) \\
41(57.6) \\
\end{array}$ & 0.235 \\
\hline $\begin{array}{l}\text { Partner education } \\
\text { No education } \\
\text { Primary } \\
\text { Secondary+ } \\
\text { Do not know } \\
\end{array}$ & $\begin{array}{c}647(46.6) \\
289(56.9) \\
181(65.7) \\
15(44.0) \\
\end{array}$ & 0.106 \\
\hline $\begin{array}{l}\text { Partner occupation } \\
\text { Have no work } \\
\text { Have work }\end{array}$ & $\begin{array}{c}11(27.9) \\
1118(51.8)\end{array}$ & 0.106 \\
\hline
\end{tabular}


TABLE 3: Continued.

\begin{tabular}{lcc}
\hline Variables & MC use, $n(\%)$ & $p$ value \\
\hline Do not know & $2(29.4)$ & \\
\hline Future fertility preference & & $<0.001$ \\
Want more soon & $155(36.8)$ & \\
Want later & $463(62.4)$ & \\
Want but time not decided & $32(52.5)$ & \\
Undecided & $67(58.1)$ & \\
Want no & $411(50.4)$ & \\
Declared infecund & $2(4.9)$ & \\
\hline Number of children ever born & & $<0.001$ \\
0 & $138(60.5)$ & \\
$1-2$ & $371(59.0)$ & \\
$3-4$ & $329(58.0)$ & \\
$\geq 5$ & $294(37.6)$ & \\
\hline Number of living children & & \\
0 & $141(60.8)$ & \\
$1-2$ & $419(58.9)$ & \\
$3-4$ & $341(54.0)$ & \\
$\geq 5$ & $231(36.6)$ & \\
\hline Ideal number of children & & \\
$\leq 3$ & $236(56.9)$ & \\
$>3$ & $785(53.2)$ & \\
Undecided & $111(35.1)$ & \\
\hline Visit health facility & $521(49.4)$ & \\
No & $611(53.1)$ & \\
Yes & & \\
\hline
\end{tabular}

The overall level of modern contraceptive use was consistent with studies done in Northwest Ethiopia (51.3\%) [22] and Sudan (51.5\%) [23]. However, it was lower compared to the study done in the Oromia region, Ethiopia, 55.7\% [24], and western Ethiopia (71.9\%) [25]. The reason for this variation might be the educational status and cultural difference of study participants. About $89 \%$ of women in the study of western Ethiopia were educated. Conversely, the prevalence of modern contraceptive use was higher compared to the previous EDHS report [26], and other studies done in Ethiopia were as follows: North Shewa Zone (46.9\%), Dabate (32.5\%), Butajira (25.4\%), Dembia District (31.7\%), and southern Central Ethiopia 31.8\%) $[20,21,27,28]$. And it also higher compared to studies done in Ghana (21.5\%) [29], Tanzania (34\%) [30], Afghanistan (29\%) [31], and FP2020 focus countries (45.7\%) [32]. This variation might be attributed to the accessibility and availability of the family planning service provision, traditional beliefs, religious, and cultural differences of study participants $[33,34]$. The most frequently mentioned reasons for not using modern contraceptives were fear of side effects, fatalistic, on breastfeeding, menses not returned, and infrequent sex or have no sex. The findings were consistent with other studies done in Ethiopia, Nigeria, and Saudi Arabia [35-38].

The proportion of women's modern contraceptive use increased with their husbands' educational level $(0.003)$. This finding was consistent with other studies $[22,27,28]$. Increasing husband's education might be helpful in a discussion on family planning and family size would increase knowledge and utilization of modern contraceptive. Modern
TABLE 4: Factors associated with modern contraceptive use among married or in-union reproductive-age women in the Amhara region, Ethiopia 2016 EDHS.

\begin{tabular}{|c|c|c|}
\hline Variables & $\operatorname{COR}(95 \% \mathrm{CI})$ & AOR $(95 \% \mathrm{CI})$ \\
\hline $\begin{array}{l}\text { Age } \\
\quad \leq 34 \\
35-49\end{array}$ & $\begin{array}{c}1 \\
0.5(0.4-0.7)\end{array}$ & $\begin{array}{c}1 \\
0.7(0.5-0.9)^{*}\end{array}$ \\
\hline $\begin{array}{c}\text { Residence } \\
\text { Urban } \\
\text { Rural } \\
\end{array}$ & $\begin{array}{c}1 \\
0.7(0.4-1.0) \\
\end{array}$ & $\begin{array}{c}1 \\
1.1(0.7-1.9) \\
\end{array}$ \\
\hline $\begin{array}{l}\text { Age at the first marriage } \\
\leq 18 \\
19-24 \\
\geq 25 \\
\end{array}$ & $\begin{array}{c}1 \\
1.4(0.9-2.0) \\
1.4(0.6-3.2) \\
\end{array}$ & $\begin{array}{l}1.0(0.6-1.7) \\
1.1(0.5-2.5) \\
\end{array}$ \\
\hline $\begin{array}{l}\text { Education status } \\
\text { No education } \\
\text { Primary } \\
\text { Secondary+ } \\
\end{array}$ & $\begin{array}{c}1 \\
1.6(1.1-2.2) \\
3.7(2.0-7.1) \\
\end{array}$ & $\begin{array}{c}1 \\
1.3(0.9-1.7) \\
3.0(1.4-6.2)^{* * *} \\
\end{array}$ \\
\hline $\begin{array}{l}\text { Wealth index } \\
\text { Poor } \\
\text { Middle } \\
\text { Rich } \\
\end{array}$ & $\begin{array}{c}1 \\
1.5(1.0-2.4) \\
1.7(1.1-2.5) \\
\end{array}$ & $\begin{array}{c}1 \\
1.6(1.0-2.5) \\
1.6(1.1-2.5)^{*} \\
\end{array}$ \\
\hline $\begin{array}{l}\text { Visited by health workers } \\
\text { No } \\
\text { Yes }\end{array}$ & $\begin{array}{c}1 \\
1.4(1.1-1.8)\end{array}$ & $1.2(0.8-1.6)$ \\
\hline $\begin{array}{l}\text { Exposed to FP message } \\
\text { No } \\
\text { Yes } \\
\end{array}$ & $\begin{array}{c}1 \\
1.4(1.0-1.9) \\
\end{array}$ & $0.8(0.6-1.7)$ \\
\hline $\begin{array}{l}\text { Family size } \\
\quad \leq 4 \\
5-8 \\
\geq 9 \\
\end{array}$ & $\begin{array}{c}1 \\
0.8(0.6-1.0) \\
0.5(0.3-0.9) \\
\end{array}$ & $\begin{array}{l}1.0(0.6-1.3) \\
0.6(0.3-1.3)\end{array}$ \\
\hline $\begin{array}{l}\text { Ideal number of children } \\
1-3 \\
3-12 \\
\text { Undecided }\end{array}$ & $\begin{array}{c}1 \\
0.9(0.6-1.2) \\
0.4(0.3-0.7)\end{array}$ & $\begin{array}{c}1 \\
1.1(0.8-1.6) \\
0.6(0.4-1.0) \\
\end{array}$ \\
\hline $\begin{array}{l}\text { Future fertility preference } \\
\text { Want more soon } \\
\text { Want } 2 \text { years later } \\
\text { Want but time not decided } \\
\text { Undecided } \\
\text { Want no more } \\
\text { Declare infecund }\end{array}$ & $\begin{array}{cc}1 \\
2.7(2.0-4.1) \\
1.9(0.9-4.1) \\
2.4(1.3-4.4) \\
1.7(1.2-2.5) \\
0.1(0.0-0.6)\end{array}$ & $\begin{array}{c}2.6(1.9-3.7)^{* * *} \\
2.3(1.0-5.4) \\
3.2(1.7-6.0)^{* * *} \\
2.4(1.6-3.5)^{* * *} \\
0.1(0.0-0.8)\end{array}$ \\
\hline
\end{tabular}

${ }^{*} p$ value $\leq 0.05,{ }^{* *} p$ value $\leq 0.01$, and ${ }^{* * *} p$ value $\leq 0.001$.

contraceptive uptake was higher among women who reported that they were exposed to FP messages (through radio, television, magazine, or phone message) and visited by health workers at home 12 months prior to the survey $(p=0.040)$. This finding was consistent with other studies $[14,39-42]$. The reason for this variation might be women received more information about family planning through mass media and during the discussion with the health workers, improving modern contraceptive methods and knowledge level along with increasing self-efficacy or empowerment in making better decisions regarding FP and contraceptive use [43]. The proportion of modern contraceptive use was higher among women who had four or less family sizes compared to women who had nine or above 
family sizes. Similarly, contraceptive use decreased with the number of living children increase. This finding was consistent with other studies. The reason might be those women who had a large number of families and children were not educated, poor, and rural residents. Not educated women and women from rural residents and poor households are having a large ideal number of children [15]. The other reason might be that women who had a large family size and living children may be aged 40 years and declared infecund.

On multivariable analysis, the age of women, future fertility preference, educational status, and household wealth index were significantly associated with modern contraceptive use. Women with secondary or higher levels of education had more odds of using modern contraceptives compared to women with not educated. This finding was in line with other studies done in Ethiopia [20, 25, 28, 44-46], Sudan [23], Ghana [29, 47, 48], and Afghanistan [31]. The reason for this might be that women's education helps them to understand their rights and responsibilities on the reproductive and sexual issues. And also it enables them to discuss with their partners and make joint decisions on FP and family size. Women empowerment is essential to improve maternal health service uptake. Also, educated women are more likely to receive family planning-related messages from different sources. Furthermore, the positive effect of education on modern contraceptive use may be associated with the delay in marriage and first pregnancy $[25,34,48-50]$.

This study revealed that women's future fertility preference was significantly associated with modern contraceptive use. The odds of modern contraceptive use among women who want no more children and want to space were higher compared to women want soon. This finding was in line with previous studies $[22,45]$. The reason might be that women who decide to delay or avoid pregnancy are internally motivated to use modern contraceptives. Aged women (women aged 35 years or more) had lower odds of using modern contraceptives. This finding was in line with studies done in Ethiopia [14], Nigeria [51], and Mali [52]. The reason might be that older women preferred traditional methods to delay or limit the number of birth [34]. This may be one of the reasons why the prevalence of unplanned pregnancy is generally higher among older women compared to younger women [50].

Women from households with the wealth index rich had higher odds of using modern contraceptives compared to those with the poor wealth index. This finding was in line with studies conducted in Ethiopia [14], Nigeria [51, 53], Angola [54], Bangladesh [39], Ghana [55], and Mali [56]. The reason for this might be direct or indirect that the costs women may incur to access contraceptives. The other reason might be the biases and misconceptions related to contraceptive use. Women may believe that contraceptives are not favorable for women involved in laborious activities, in which poor women usually engage in. Exposure to family planning messages through mass media may be the other reason, which showed a significant association with contraceptive use in other studies [39-42], in which rich women are accessible for it.

\section{Conclusions}

Modern contraceptive use among married or in-union reproductive-age women was relatively high compared to other studies done in the region. Age of women, educational status, future fertility preference, and wealth index were statistically significant factors associated with modern contraceptive use. Strengthening women's and community education may improve modern contraceptive use. Health care providers should be given special attention for women aged 30 and 40 years when they provide family planning counseling. Also, more emphasis should be given to income generation activities.

\section{Data Availability}

The data used for this analysis are available in the repository (https://dhsprogram.com/data), upon permission from the DHS program.

\section{Ethical Approval}

The 2016 EDHS protocol was reviewed and approved by the Federal Democratic Republic of Ethiopia Ministry of Science and Technology and the Institutional Review Board of ICF International.

\section{Conflicts of Interest}

The authors declare that they have no conflicts of interest.

\section{Authors' Contributions}

MBA conceived, designed, and performed the analysis. GWD, GAF, and YMG were equally involved in the analysis, interpretation, and writing of the results. All authors read and approved the final manuscript.

\section{Acknowledgments}

The authors would like to acknowledge the DHS program for allowing to use the data.

\section{References}

[1] L. Alkema, V. Kantorova, C. Menozzi, and A. Biddlecom, "National, regional, and global rates and trends in contraceptive prevalence and unmet need for family planning between 1990 and 2015: a systematic and comprehensive analysis," The Lancet, vol. 381, no. 9878, pp. 1642-1652, 2013.

[2] Wolrd Health Organization (WHO), 2014, https://www.who. int.

[3] L. Liu, S. Becker, A. Tsui, and S. Ahmed, "Three methods of estimating births averted nationally by contraception," Population Studies, vol. 62, no. 2, pp. 191-210, 2008.

[4] S. Singh, J. E. Darroch, L. S. Ashford, and M. Vlassoff, Adding it up: The Costs and Benefits of Investing in Family Planning and Maternal and Newborn Health, Guttmacher Institute and United Nations Population Fund, New York, NY, USA, 2009.

[5] S. Ahmed, Q. Li, L. Liu, and A. O. Tsui, "Maternal deaths averted by contraceptive use: an analysis of 172 countries," The Lancet, vol. 380, no. 9837, pp. 111-125, 2012. 
[6] Department of Economic and Social Affairs and World Family Planning, World Family Planning 2017-Highlights (ST/ESA/SER.A/414), World Health Organisation, Geneva, Switzerland, 2017.

[7] World Health Organization, Family planning/ Contraception-WHO, World Health Organisation, Geneva, Switzerland, 2019.

[8] J. Bearak, A. Popinchalk, L. Alkema, and G. Sedgh, "Global, regional, and subregional trends in unintended pregnancy and its outcomes from 1990 to 2014: estimates from a Bayesian hierarchical model," The Lancet Global Health, vol. 6, no. 4, pp. e380-e389, 2018.

[9] A. Glasier, A. M. Gülmezoglu, G. P. Schmid, C. G. Moreno, and P. F. Van Look, "Sexual and reproductive health: a matter of life and death," The Lancet, vol. 368, no. 9547, pp. 15951607, 2006.

[10] A. Kesetebirhan, National Guideline for Family Planning Services in Ethiopia, The Federal Democratic Republic of Ethiopia, Ministry of Health, Addis Ababa, Ethiopia, 2011.

[11] FMoH, Health-Related Indicator of Ethiopia, Federal Ministry of Health, Addis Ababa, Ethiopia, 2006.

[12] Federal Democratic Republic of Ethiopia Ministry of Health, HSTP Health Sector Transformation Plan 2015/16-2019/20 (2008-2012 EFY), Federal Democratic Republic of Ethiopia Ministry of Health, Addis Ababa, Ethiopia, 2015.

[13] Central Statistical Agency (Ethiopia), Ethiopia Mini Demographic and Health Survey 2019, Addis Ababa: Central Statistical Agency (Ethiopia), Addis Ababa, Ethiopia, 2019.

[14] Y. Lakew, "Geographical variation and factors influencing modern contraceptive use among married women in Ethiopia: evidence from a national population-based survey," Reproductive Health, vol. 10, no. 1, p. 52, 2013.

[15] EDHS, Demographic and Health Survey 2016: Key Indicators Report, The DHS Program ICF, Ethiopia, 2016.

[16] A. T. Tsegaye, M. Mengistu, and A. Shimeka, "Prevalence of unintended pregnancy and associated factors among married women in west Belessa Woreda, Northwest Ethiopia," Reproductive Health, vol. 15, no. 1, p. 201, 2018.

[17] E. Admasu, "Level of unintended pregnancy among reproductive-age women in Bahir Dar city administration, Northwest Ethiopia," BMC Research Notes, vol. 11, no. 1, p. 891, 2018.

[18] F. Yenealem and G. Niberet, "Prevalence and associated factors of unintended pregnancy among pregnant women in Gondar town, Northwest Ethiopia, 2014," BMC Research Notes, vol. 12, no. 1, p. 161, 2019.

[19] A. Haile, "Unintended conception and unwanted fertility in Gondar, Ethiopia," East African Medical Journal, vol. 69, no. 7, pp. 355-359, 1992.

[20] G. A. Alemayehu, "Prevalence and determinants of contraceptive utilization among married women at dabat health and demographic surveillance system site, northwest Ethiopia," BMC Women's Health, vol. 18, no. 1, p. 118, 2018.

[21] S. Debebe, M. Andualem Limenih, and B. Biadgo, "Modern contraceptive methods utilization and associated factors among reproductive aged women in rural Dembia District, northwest Ethiopia: community based cross-sectional study," International Journal of Reproductive BioMedicine, vol. 15, no. 6, pp. 367-374, 2017.

[22] A. Gebremariam and A. Addissie, "Modern contraceptive method mix and factors affecting utilization of modern contraceptives among married women in Adigrat town, Tigray, Northern Ethiopia," Family Medicine \& Medical Science Research, vol. 3, no. 4, pp. 139-143, 2014.
[23] A. H. Ibnouf, H. W. Van den Borne, and J. A. M. Maarse, "Utilization of family planning services by married Sudanese women of reproductive age," Eastern Mediterranean Health Journal, vol. 13, no. 6, pp. 1372-1381, 2007.

[24] A. Kebede, "Factors affecting demand for modern contraceptives among currently married reproductive age women in rural Kebeles of Nunu Kumba district, Oromia, Ethiopia," Contraception and Reproductive Medicine, vol. 4, no. 1, p. 21, 2019.

[25] T. Tekelab, A. S. Melka, and D. Wirtu, "Predictors of modern contraceptive methods use among married women of reproductive age groups in Western Ethiopia: a community based cross-sectional study," BMC Women's Health, vol. 15, no. 1, p. 52, 2015.

[26] CSA-Ethiopia, International: Ethiopia Demographic and Health Survey 2011. Central Statistical Agency of Ethiopia and ICF International Addis Ababa, CSA-Ethiopia, Calverton, MD, USA, 2012.

[27] A. Mohammed, "Determinants of modern contraceptive utilization among married women of the reproductive age group in North Shoa Zone, Amhara Region, Ethiopia," Reproductive Health, vol. 11, no. 1, p. 13, 2014.

[28] W. Mekonnen and A. Worku, "Determinants of low family planning use and high unmet need in Butajira district, south central Ethiopia," Reproductive Health, vol. 8, no. 1, p. 37, 2011.

[29] P. A. Aviisah, "Modern contraceptive use among women of reproductive age in Ghana: analysis of the 2003-2014 Ghana demographic and health surveys," BMC Women's Health, vol. 18, no. 1, p. 141, 2018.

[30] E. J. Michael, Use of Contraceptives Methods Among Women in Stable Marital Relations Attending Health Facilities in Kahama District, Shinyanga Region, Muhimbili University of Health and Allied Sciences, Salaam, Tanzania, 2012.

[31] S. Ajmal, A. Idris, and B. Ajmal, "Factors affecting contraceptive use and unmet need among currently married women in Afghanistan: further analysis of the 2015 Afghanistan demographic and health survey," Journal of Global Health Reports, vol. 2, 2018.

[32] N. Cahill, E. Sonneveldt, J. Stover et al., "Modern contraceptive use, unmet need, and demand satisfied among women of reproductive age who are married or in a union in the focus countries of the family planning 2020 initiative: a systematic analysis using the family planning estimation tool," The Lancet, vol. 391, no. 10123, pp. 870-882, 2018.

[33] A.-R. Omran, Family Planning in the Legacy of Islam, Routledge, Abingdon, UK, 2012.

[34] NIPORT, Bangladesh Demographic and Health Survey, 2007, NIPORT, Dhaka, Bangladesh, 2009.

[35] B. A. Oye-Adeniran, I. F. Adewole, A. V. Umoh et al., "Community-based study of contraceptive behaviour in Nigeria," African Journal of Reproductive Health, vol. 10, no. 2, pp. 90-104, 2006.

[36] A. Tadele, D. Abebaw, and R. Ali, "Predictors of unmet need for family planning among all women of reproductive age in Ethiopia," Contraception and Reproductive Medicine, vol. 4, no. 1, p. 6, 2019.

[37] E. Genet, G. Abeje, and T. Ejigu, "Determinants of unmet need for family planning among currently married women in Dangila town administration, Awi Zone, Amhara regional state; a cross-sectional study," Reproductive Health, vol. 12, no. 1, p. 42, 2015.

[38] S. N. Khalil, M. M. Alzahrani, and A. F. Siddiqui, "Unmet need and demand for family planning among married women 
of Abha, Aseer Region in Saudi Arabia," Middle East Fertility Society Journal, vol. 23, no. 1, pp. 31-36, 2018.

[39] I. Haq, S. Sakib, and A. Talukder, "Sociodemographic factors on contraceptive use among ever-married women of reproductive age: evidence from three demographic and health surveys in Bangladesh," Medical Sciences, vol. 5, no. 4, p. 31, 2017.

[40] A. Kabir, "Determinants of the current use of contraceptive methods in Bangladesh," Journal of Medical Sciences (Faisalabad), vol. 1, no. 5, pp. 296-301, 2001.

[41] A. K. Osmani, "Factors influencing contraceptive use among women in Afghanistan: secondary analysis of Afghanistan health survey 2012," Nagoya Journal of Medical Science, vol. 77, no. 4, p. 551, 2015.

[42] R. D. Retherford and V. K. Mishra, "Media exposure increases contraceptive use," National Family Health Survey Bulletin, vol. 7, pp. 1-4, 1997.

[43] A. M. Aguilar Rivera and R. Cortez, Family Planning: The Hidden Need of Married Adolescents in Nepal, Technical Report, World Bank Group, Washington, DC, USA, 2015.

[44] J. Gizachew Balew, Y. Cho, C. T. Kim, and W. Ko, "Structural determinants in family planning service utilization in Ethiopia: EDHS 2011 analysis," BioMed Research International, vol. 2015, Article ID 495745, 17 pages, 2015.

[45] A. G. Worku, G. A. Tessema, and A. A. Zeleke, Trends and Determinants of Contraceptive Use among Young Married Women (Age 15-24) Based on 2000, 2005, and 2011 Ethiopia Demographic and Health Surveys: A Multivariate Decomposition Analysis, ICF International, Fairfax, VA, USA, 2014.

[46] A. B. Geremew and A. A. Gelagay, "Modern contraceptive use and associated factors among married women in Finote selam town Northwest Ethiopia: a community based cross-sectional study," Women's Midlife Health, vol. 4, no. 1, p. 13, 2018.

[47] S. Eliason, "Determinants of modern family planning use among women of reproductive age in the Nkwanta district of Ghana: a case-control study," Reproductive Health, vol. 11, no. 1, p. 65, 2014.

[48] P. A. Apanga and M. A. Adam, "Factors influencing the uptake of family planning services in the Talensi district, Ghana," Pan African Medical Journal, vol. 20, no. 1, 2015.

[49] M. A. Habib, "Prevalence and determinants of unintended pregnancies amongst women attending antenatal clinics in Pakistan," BMC Pregnancy and Childbirth, vol. 17, no. 1, p. 156, 2017.

[50] S. A. Ali, S. S. Tikmani, and W. Qidwai, "Prevalence and determinants of unintended pregnancy: a systematic review," World Family Medicine Journal: Incorporating the Middle East Journal of Family Medicine, vol. 99, no. 3671, pp. 1-10, 2016.

[51] A. Arbab, A. Bener, and M. Abdulmalik, "Prevalence, awareness, and determinants of contraceptive use in qatari women," Eastern Mediterranean Health Journal, vol. 17, no. 1, pp. 11-18, 2011.

[52] E. B. Kaggwa, N. Diop, and J. D. Storey, "The role of individual and community normative factors: a multilevel analysis of contraceptive use among women in-union in Mali," International Family Planning Perspectives, vol. 34, no. 2, pp. 7988, 2008.

[53] S. Viswan, S. Ravindran, N.-B. Kandala, M. Petzold, and S. Fonn, "Sexual autonomy and contraceptive use among women in Nigeria: findings from the Demographic and Health Survey data," International Journal of Women's Health, vol. Volume 9, pp. 581-590, 2017.
[54] M. Decker and N. A. Constantine, "Factors associated with contraceptive use in Angola," African Journal of Reproductive Health, vol. 15, no. 4, pp. 68-77, 2011.

[55] H. P. Crissman, R. M. Adanu, and S. D. Harlow, "Women's sexual empowerment and contraceptive use in Ghana," Studies in Family Planning, vol. 43, no. 3, pp. 201-212, 2012.

[56] S. A. Adebowale, "Differential effect of wealth quintile on modern contraceptive use and fertility: evidence from Malawian women," BMC Women's Health, vol. 14, no. 1, p. 40, 2014. 